\title{
The use of roflumilast in COPD: a primary care perspective
}

\author{
*David Price ${ }^{\mathrm{a}, \mathrm{b}}$, Alison Chisholma, Dermot Ryanc, Alan Crockett ${ }^{\mathrm{d}}$, Rupert Jones \\ a Research in Real Life Ltd, Old Winery Business Park, Cawston, Norwich, UK \\ ${ }^{\mathrm{b}}$ Centre of Academic Primary Care, University of Aberdeen, Foresterhill Health Centre, Westburn Road, Aberdeen, UK \\ ' Woodbrook Medical Centre, Loughborough, UK \\ ${ }^{d}$ Discipline of General Practice, School of Population Health \& Clinical Practice, The University of Adelaide, Adelaide, South Australia \\ e Department of Primary Care, Peninsula Medical School, University of Plymouth, Devon, UK
}

Originally submitted 27th July 2010; resubmitted 2nd September 2010; revised version received 27th September 2010;

accepted 1st October 2010; online 17th November 2010

\begin{abstract}
Therapeutic interventions in chronic obstructive pulmonary disease (COPD) shown to reduce exacerbations include smoking cessation, vaccination and appropriate pharmacological therapy. Long-acting bronchodilators are the cornerstone of COPD pharmacotherapy, whereas inhaled corticosteroids and mucolytics have shown benefit in subgroups of patients. Despite management with existing therapies, clinical trials confirm the persistent nature of exacerbations throughout the course of the disease. Roflumilast - a phosphodiesterase-4 (PDE4) inhibitor - received European Marketing Approval in 2010 and represents a new class of drug in the management of COPD. Through selective inhibition of the PDE4 enzyme, roflumilast prevents the breakdown of cyclic AMP, which plays an important role in regulating inflammatory cell activity. Early trials in patients with a forced expiratory volume in one second (FEV 1 ) less than $50 \%$ predicted suggest that roflumilast offers sustained and significant improvement in lung function and a reduction in exacerbations compared with placebo, irrespective of concomitant bronchodilator therapy. Common adverse events include headache, diarrhoea and weight loss, with the majority occurring at the beginning of treatment, being transient and not leading to sequelae. Serious adverse events tended to be low across all studies. Roflumilast is currently licensed in Europe, and is indicated as maintenance treatment in severe COPD (i.e. in patients with post-bronchodilator FEV $1<50 \%$ predicted) associated with chronic bronchitis in adult patients with a history of frequent exacerbations as an add-on to bronchodilator treatment. Clear identification of patients eligible for roflumilast will require improved characterisation and phenotyping of patients in primary care, including lung function measurement, accurate health status classification, and recording of chronic cough and regular sputum production.

(C) 2010 Primary Care Respiratory Society UK. All rights reserved.

D Price et al. Prim Care Resp J 2010; 19(4): 342-351

doi:10.4104/pcrj.2010.00066
\end{abstract}

Keywords COPD, severe, exacerbations, phenotypes, chronic bronchitis, maintenance treatment, PDE4 inhibitors, roflumilast, primary care, RCT evidence

\section{Contents}

Abstract

Introduction …

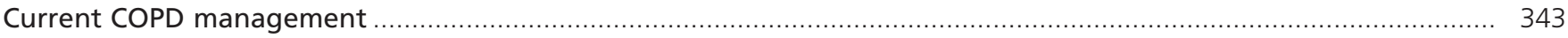

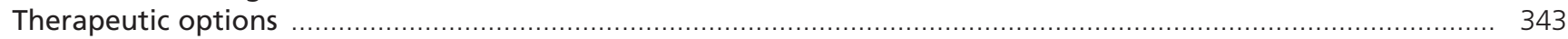

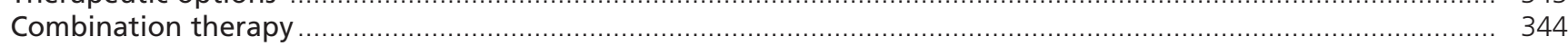

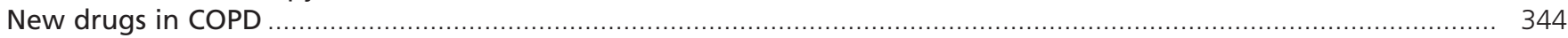

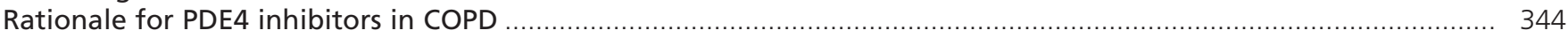

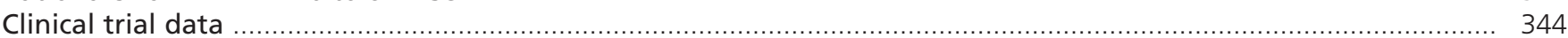

1. AURA and HERMES …

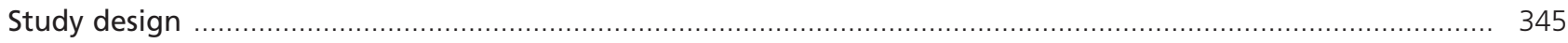

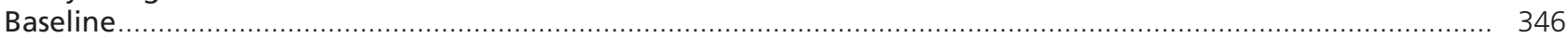

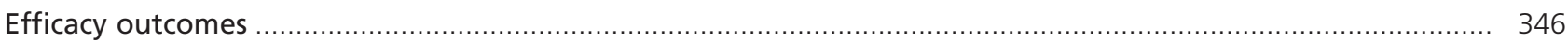

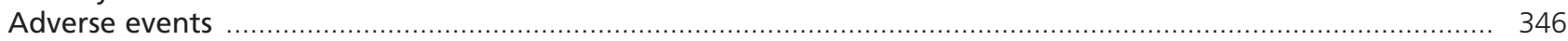

* Corresponding author: Professor David Price, Centre of Academic Primary Care, University of Aberdeen, Foresterhill Health Centre, Westburn Road, Aberdeen, Scotland, AB25 2AY, UK. Tel: +44 (0)1224 554588 Fax: +44 (0)1224 840683 E-mail: david@respiratoryresearch.org 


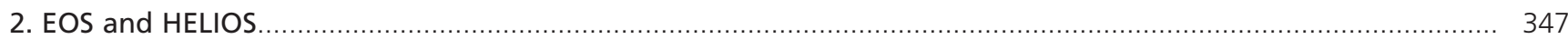

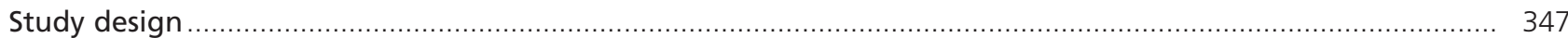

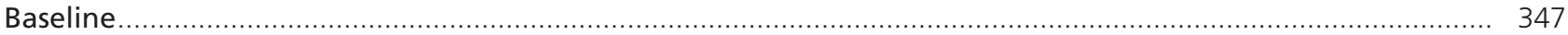

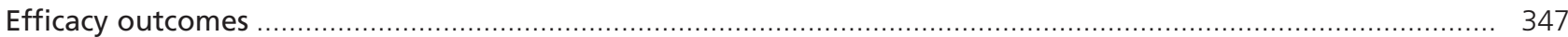

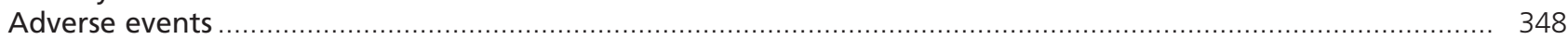

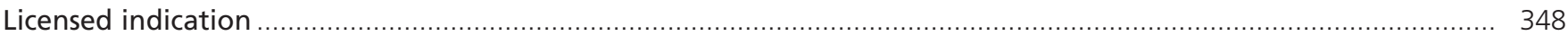

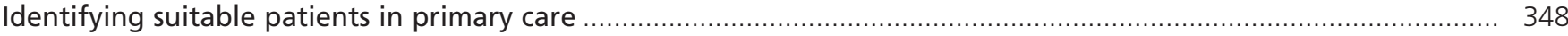

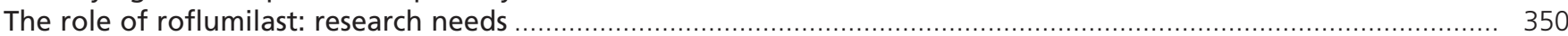

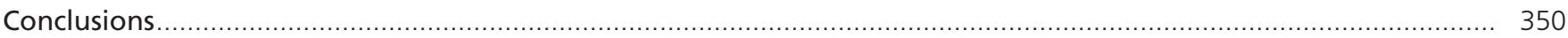

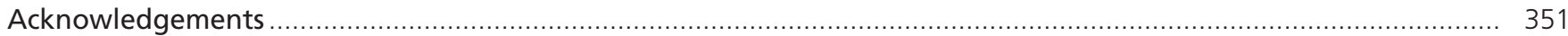

\section{Introduction}

COPD is a progressive, largely irreversible respiratory disease associated with high morbidity and a limited long-term prognosis. It is characterised by a progressive decline in lung function and irreversible airway obstruction. COPD incorporates the processes of emphysema (alveolar destruction) and chronic bronchitis (airway inflammation and scarring). The pathological changes in the lung are associated with important systemic features mediated by acute phase immune activation leading, in some cases, to weight loss, malaise and fatigue. These systemic features are aggravated during acute exacerbations of COPD.

The World Health Organisation (WHO) estimates that approximately 80 million people worldwide have COPD and predictions are that it will be the third leading cause of death by 2030.' It has a substantial impact on healthcare resources despite being a frequently mis- and under-diagnosed condition.? A recent screening study found that nearly a fifth of smokers and a quarter of asthma patients aged over 40 had spirometricallydefined COPD despite having no recorded COPD diagnosis. ${ }^{3}$

In contrast to asthma, which is an episodic, rarely lifethreatening disease with effective controller and reliever therapies available, COPD is a progressive, debilitating condition. Early identification, diagnosis and prompt therapeutic interventions are fundamental to optimising treatment response. ${ }^{4}$ Short-acting bronchodilators can reduce breathlessness and limitations on exercise capacity. Regardless of airway obstruction, maintenance therapy with long-acting bronchodilators in patients who continue to have symptoms can help manage airflow limitation and symptoms, ${ }^{4-9}$ and regular inhaled corticosteroid (ICS) therapy can reduce exacerbation rates in patients who continue to experience exacerbations despite maintenance therapy with one or more long-acting bronchodilators. $^{4-9}$

Roflumilast, a phosphodiesterase-4 (PDE4) inhibitor, received European Marketing Approval in 2010 and represents a new COPD drug class. By selective inhibition of PDE4, it prevents the breakdown of cyclic AMP which plays an important role in regulating inflammatory cell activity. Early trials in patients with severe COPD suggest that roflumilast offers sustained and significant improvement in lung function and a reduction in exacerbations compared with placebo, irrespective of concomitant bronchodilator therapy. This review discusses the rationale for treatment with PDE4 inhibitors, summarises current evidence for the use of roflumilast in selected COPD patients, and highlights future research needs such as improved characterisation and phenotyping of COPD patients in primary care.

\section{Current COPD management Therapeutic options}

Among COPD patients who smoke, smoking cessation advice and (where appropriate) pharmacotherapy are an integral part of slowing disease progression and reducing symptoms, particularly in early-stage, milder disease. Frequently, patients with COPD have strong nicotine dependence - often stronger than that seen among smokers without COPD - suggesting that smokers with COPD will struggle to quit and are likely to benefit from greater support, including pharmacological smoking cessation interventions. ${ }^{10}$

Once smoking cessation and influenza vaccination (i.e. active reduction of risk factors) has been addressed, the Global Initiative for chronic Obstructive Lung Disease (GOLD) recommends a stepwise approach to pharmacological treatment. ${ }^{5}$ For patients with less severe disease, early introduction of short-acting bronchodilator therapy (i.e. shortacting $\beta_{2}$-agonists [SABAs] and / or short-acting muscarinic antagonists [SAMAs]) is recommended to improve health status (i.e. reduce symptoms, exacerbations, activity limitation and deconditioning). For those whose symptoms are not fully controlled on short-acting therapy and/or in those with more advanced disease, ${ }^{5}$ progression to regular treatment with longacting bronchodilator(s) (long-acting $\beta_{2}$-agonists [LABAs], longacting muscarinic antagonists [LAMA]), or theophylline) is recommended. Where patients still continue to experience multiple COPD exacerbations annually, despite long-acting bronchodilator therapy, the addition of ICS is advised. For those with chronic viscous sputum, the addition of mucolytic therapy may be beneficial, but the likely overall benefits are thought to be small. 5,11

Pulmonary rehabilitation (tailored to the individual needs of the patient) is recommended in moderate and severe COPD - in clinical practice this tends to be interpreted as those patients with a Medical Research Council (MRC) dyspnoea score of 3 or 


\begin{tabular}{cl} 
Table 1. Medical Research Council dyspnoea scale. ${ }^{12}$ \\
Grade & Degree of breathlessness related to activities \\
\hline 1 & Not troubled by breathlessness except on strenuous exercise \\
\hline 2 & Short of breath when hurrying or walking up a slight hill \\
\hline 3 & $\begin{array}{l}\text { Walks slower than contemporaries on level ground because } \\
\text { of breathlessness, or has to stop for breath when walking } \\
\text { at own pace }\end{array}$ \\
\hline 4 & $\begin{array}{l}\text { Stops for breath after walking about 100m or after a few } \\
\text { minutes on level ground }\end{array}$ \\
\hline 5 & $\begin{array}{l}\text { Too breathless to leave the house, or breathless when } \\
\text { dressing or undressing }\end{array}$ \\
\hline $\begin{array}{l}\text { Reprinted from The British Medical Journal, volume 2, Fletcher CM, et al. } \\
\text { Significance of Respiratory Symptoms and the Diagnosis of Chronic Bronchitis } \\
\text { in a Working Population, 257-66, Copyright (1959), with permission from } \\
\text { BMJ Publishing Group Ltd }\end{array}$
\end{tabular}

more (see Table 1) - irrespective of concomitant drug therapy. Long-term oxygen therapy (LTOT) and surgery (e.g. lung volume reduction surgery) are options available for late-stage disease. ${ }^{5}$

\section{Combination therapy}

$\beta_{2}$-agonists, muscarinic antagonists and ICS therapies all have different modes of action and are thought to act in an additive way. Indeed, data suggest that combination therapy offers better treatment outcomes than individual therapies. Effective combinations of COPD therapies have been identified: 6

- $\beta_{2}$-agonist (i.e. short-acting [SABA] or long-acting [LABA]) and anticholinergic (i.e. short-acting [SAMA] or long-acting [LAMA])

- SABA or LABA and theophylline

- SAMA or LAMA and theophylline

- LABA and ICS.

Beyond these guideline-endorsed combinations, there are data to suggest that triple therapy may also be beneficial. ${ }^{13}$ In a study by singh et al., fixed dose combination ICS/LABA (salmeterol/fluticasone [SFC]) plus LAMA (tiotropium [Tio]) led to greater improvements in bronchodilation compared with Tio or SFC alone. The therapeutic advantages were observed across a range of physiologically important parameters, including airway conductance and lung volumes. Triple therapy also led to patient-related benefits by improving transition dyspnoea indices (TDI) and use of rescue medication. ${ }^{13}$

\section{New drugs in COPD}

The future of exacerbation prevention is in assessment and identification of optimum combinations of pharmacological and non-pharmacological therapies that will improve health status and reduce hospital admissions and mortality associated with COPD.

A new class of drug - phosphodiesterase-4 (PDE4) inhibitors - which works on the pathophysiological mechanism of COPD has recently been added to the treatment armamentarium, the PDE4 inhibitor roflumilast. $14,15,16$

\section{Rationale for PDE4 inhibitors in COPD}

COPD is a complex disease with many inflammatory pathways that initiate and potentiate the disease process. ${ }^{17-22}$ Cyclic AMP (CAMP) plays an important role in regulating inflammatory cell activity. The PDE4 enzyme catalyses CAMP degradation into an inactive compound. PDE4 inhibitors bind to the PDE4 enzyme and prevent the breakdown of CAMP, thus maintaining intracellular CAMP levels while reducing the cell's inflammatory activity. PDE4 inhibitors have potential to reduce inflammatory-mediated processes including small airway thickening, emphysematous destruction, mucociliary malfunction, oxidative stress, and pulmonary vascular remodelling. ${ }^{23}$

However, while ex vivo and in vivo cell-based assays and animal-based evaluations of PDE inhibitors provide useful information on the possible effects of PDE4 in humans, the predictive value of such pharmacology-based assessments and animal models of smoking damage are limited. Based on the data available, the clinical expectation of PDE4 inhibition is an effect on the underlying inflammation seen in COPD.

\section{Clinical trial data}

Phase II and III trial data suggest that roflumilast works independently of traditional COPD therapies (there may be a potential overlap with xanthines that has yet to be determined and quantified; see section below on 'Future research needs') and appears to offer additional benefits (e.g. reduced exacerbations and improved lung function) when used in combination with current drugs. ${ }^{14,15}$

More than 10,000 patients with varying degrees of COPD severity took part in roflumilast's pre-licence clinical trial programme (M2-124 [clinical trial number NCT00297102; "AURA"]; M2-125 [NCT00297115; "HERMES"]; M2-127 [NCT00313209; "EOS"]; M2-128 [NCT00424268; "HELIOS"]). Patient selection was guided by a pooled analysis of early trial work (studies M2-111 ["OPUS"] and M2-112 ["RATIO"]), which defined "roflumilast responders" as patients with a symptom profile corresponding to chronic bronchitis, who were prone to exacerbations and had an FEV $1<50 \%$ predicted. ${ }^{24}$ The phenotypic approach used to inform the pre-licence trial programme resulted from disappointing early trial work. ${ }^{24}$ In the early trials roflumilast significantly reduced the exacerbation rate (by $26.2 \%$; $\mathrm{p}=0.001)$ compared with placebo in patients with chronic bronchitis with or without emphysema, but no effect on exacerbation rate was seen in patients with emphysema only $(-1.1 \% ; p=0.93)$. Thus patients with the common chronic bronchitis phenotype were identified as likely responders when designing the later trials. ${ }^{24}$ Phenotypic patient characterisation and recruitment has been seen previously in asthma (e.g. in omalizumab trial work) but is new to COPD. ${ }^{25}$ 


\section{AURA and HERMES}

\section{Study design}

AURA and HERMES ${ }^{14}$ were two one-year trials of identical design that investigated whether roflumilast would reduce the frequency of moderate and severe COPD exacerbations compared with placebo over one year. Entry criteria were defined as $\geq 1$ documented moderate or severe COPD exacerbation in the previous year, where a moderate exacerbation was managed by initiating oral or parenteral glucocorticosteroid and a severe exacerbation required hospitalisation and/or resulted in death. Additionally, data were collected for the total number of COPD exacerbations, defined as above together with episodes treated with antibiotics alone.

Eligible patients had to be over 40 years of age, have COPD with associated chronic bronchitis, $\mathrm{FEV}_{1} \leq 50 \%$ predicted, with a total cough and sputum score of $\geq 14$ [which could be achieved due to cough alone where patients scored a daily average of 2 of 3 points on the cough score] in the week directly preceding randomisation (see Figure ${ }^{14}$ ), and needed to have a history of exacerbations.

Patients were allowed concomitant SAMA (approximately 40\% of patients) and LABA (approximately $50 \%$ of patients) medication.

Figure 1. Reproduction of the symptom daily diary card (and instructions for completion) used to evaluate cough and sputum score. ${ }^{14}$

\section{Completion of the diary}

- Each entry page consists of 3 sheets: one white original and two coloured copies (pink and yellow). As self-copying paper is being used, you should take care to the following:

- Please make entries only on the white original, and do not remove any pages

- Use a black ball-point pen to ensure that entries are transcribed onto the copy

- $\quad$ Please enter the year on each page

- Please enter daily into the diary

- Date (day and month [dd/mm])

- Cough score and sputum production score. Please add up the numbers to "Total"

- Number of puffs of rescue medication you did inhale during the give 2 time periods (number of puffs means number of actuations taken from your rescue medication inhaler). Please add up the numbers to "Total". Cough, sputum production In the evening, please assess your symptoms of cough and sputum production for the last 24 hours. Please enter the number
" 0 " into the respective box if you have no symptoms.

No. of puffs rescue Medication If no rescue medication was taken, enter the number " 0 " into the respective box

\begin{tabular}{|l|l|l|l|l|l|l|l|l|}
\hline $\begin{array}{l}\text { Date } \\
\text { Year }\end{array}$ & & & & & & & & \\
\hline & {$[\mathrm{dd} \mid \mathrm{mm}]$} & {$[\mathrm{dd} \mid \mathrm{mm}]$} & {$[\mathrm{dd} \mid \mathrm{mm}]$} & {$[\mathrm{dd} \mid \mathrm{mm}]$} & {$[\mathrm{dd} \mid \mathrm{mm}]$} & {$[\mathrm{dd} \mid \mathrm{mm}]$} & {$[\mathrm{dd} \mid \mathrm{mm}]$} & {$[\mathrm{dd} \mid \mathrm{mm}]$} \\
\hline
\end{tabular}

\begin{tabular}{|l|l|l|l|l|l|l|l|}
\hline Cough* $^{*}$ & & & & & & \\
\hline Sputum production** & & & & & & & \\
\hline Total & & & & & & & \\
\hline
\end{tabular}

\section{*Cough: How was your cough today?}

0 No cough

1 Mild cough (at some time during the day)

2 Moderate cough (regularly during the day)

3 Severe cough (never free of cough or feeling free of the need to cough)
**Sputum production: Hum much inconvenience was caused by your sputum today?

0 None (unnoticeable)

1 Mild (noticeable as a problem)

2 Moderate (frequent inconvenience)

3 Severe (constant problem)

Note: $\quad$ Please add up your "Totals" for each day

Please contact your study doctor whenever your condition worsens, for example:

- Increased cough and/or sputum

- Increased need of rescue medication

$\Rightarrow$ How many puffs of your rescue medication did you take today? (Record the number of puffs taken during each time period noted).

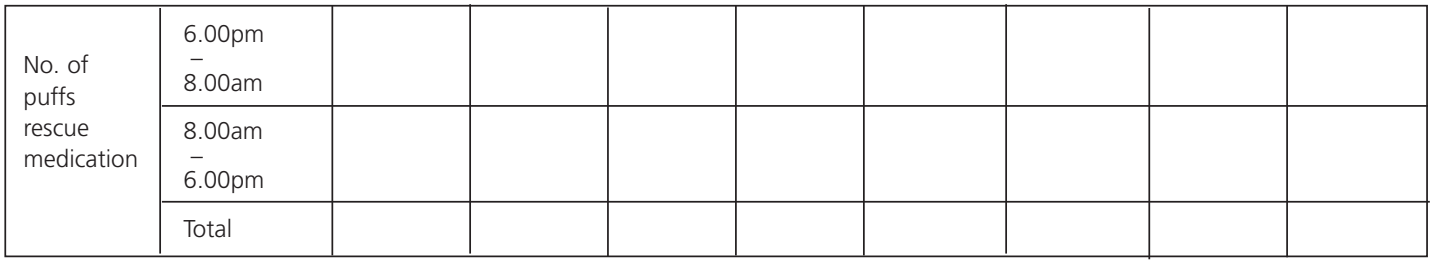

Reprinted from The Lancet, volume 374, Calverley PM, Rabe KF, Goehring UM, et al. Roflumilast in symptomatic chronic obstructive pulmonary disease: two randomised clinical trials, pages 685-94 (Online Supplement), Copyright (2009), with permission from Elsevier 


\section{Baseline}

The patient populations in both studies were very similar at baseline - tending to be heavy smokers with poor lung function and low reversibility, predominantly male and largely defined as severe by the GOLD criteria. ${ }^{5}$ However, patients in HERMES appeared to have slightly more advanced disease compared with those in AURA (see Table 2a).

\section{Efficacy outcomes}

The pooled analysis of AURA and HERMES found sustained and statistically significant improvement in lung function in patients treated with roflumilast compared with placebo - a mean change in pre-bronchodilator $\mathrm{FEV}_{1}$ in the roflumilast patients (relative to placebo) of $48 \mathrm{~mL}(p<0.0001)(39 \mathrm{~mL}$ in AURA $[p=0.0003]$; $58 \mathrm{~mL}$ in HERMES $[p<0.0001])$. Statistically significant differences in pre-bronchodilator $\mathrm{FEV}_{1}$ were seen between the roflumilast and placebo arms of both studies at all time points. The phenotypic characterisation of patients included in the study was associated with a significant reduction in exacerbations of $16-21 \%$ and was seen across both studies (see Table 2a). Overall, the number of patients needed to treat (NNT) with roflumilast to prevent one moderate or severe exacerbation per year was 5.29 in AURA and 3.64 in HERMES.

No apparent acute bronchodilator effect was seen with roflumilast in these studies, suggesting that the treatment effect is achieved through an anti-inflammatory mode of action rather than through bronchodilation. This observation is supported by the absence of a preferential drop-out rate (see section on 'Adverse events' below) and the similarity in patient-reported quality of life EuroQoL (EQ-5D) (standardised patient-completed health outcome questionnaire) between the two treatment arms, which suggests that patients were not aware of any immediate, beneficial treatment effect.

\section{Adverse events}

Across both studies, there was no difference in cardiovascular events or pneumonia between the roflumilast and placebo treatment arms. While adverse events were more common with roflumilast than placebo (reported in $67 \%$ and $62 \%$ of patients, respectively), serious adverse events were low (19\% of roflumilast patients, $22 \%$ placebo) and discontinuation as a result of adverse events was more common in the pooled roflumilast groups than in the pooled placebo groups (14\% vs $11 \%)$. The most frequently cited reasons for discontinuation were diarrhoea, nausea and headache. These adverse events tended to be most evident in the first 4-12 weeks of treatment when they contributed to the early difference in withdrawal rates between the studies. After this time, no difference in the occurrence of these adverse events was noted between roflumilast and placebo arms. Furthermore, while the incidence

Table 2a. Summary of roflumilast Phase II and III clinical trials, AURA and HERMES. ${ }^{15}$

\begin{tabular}{|c|c|c|c|c|}
\hline & & & AURA & HERMES \\
\hline \multirow{6}{*}{ Study Design } & \multirow{2}{*}{\multicolumn{2}{|c|}{ Treatment }} & \multicolumn{2}{|c|}{ - roflumilast $(n=1,537)$ versus placebo $(n=1,554)$} \\
\hline & & & $\begin{array}{l}\text { - roflumilast }(n=765) \\
\text { - placebo }(n=758)\end{array}$ & $\begin{array}{l}\text { - roflumilast }(n=771) \\
\text { - placebo }(n=796)\end{array}$ \\
\hline & \multicolumn{2}{|c|}{ Roflumilast dose } & \multicolumn{2}{|l|}{$500 \mathrm{mcg}$} \\
\hline & \multicolumn{2}{|c|}{ Study duration } & \multicolumn{2}{|l|}{52 weeks } \\
\hline & \multicolumn{2}{|c|}{ Population } & \multicolumn{2}{|c|}{$\begin{array}{l}\text { - }>40 \text { years } \\
\text { - chronic bronchitis } \\
\text { - } \mathrm{FEV}_{1} \leq 50 \% \text { predicted } \\
\text { - Total cough and sputum score } \geq 14 \\
\text { - history of exacerbations }\end{array}$} \\
\hline & \multicolumn{2}{|c|}{ Primary endpoints } & \multicolumn{2}{|c|}{$\begin{array}{l}\text { - Change in pre-bronchodilator } \mathrm{FEV}_{1} \\
\text { - Exacerbations }\end{array}$} \\
\hline \multirow{4}{*}{ Baseline } & \multicolumn{2}{|l|}{ Age } & 64 years & 64 years \\
\hline & \multirow{2}{*}{$\begin{array}{l}\text { COPD } \\
\text { severity } \\
\text { by } \mathrm{FEV}_{1} \text { * }\end{array}$} & Severe & $65 \%$ & $60 \%$ \\
\hline & & Very severe & $25 \%$ & $33 \%$ \\
\hline & \multicolumn{2}{|c|}{ Gender (male) } & $71 \%$ & $80 \%$ \\
\hline \multirow{4}{*}{ Outcomes } & \multirow{2}{*}{\multicolumn{2}{|c|}{$\begin{array}{l}\text { Mean change in pre-bronchodilator } \mathrm{FEV}_{1} \\
\text { relative to placebo arm }\end{array}$}} & $39 \mathrm{~mL}$ & $58 \mathrm{~mL}$ \\
\hline & & & \multicolumn{2}{|l|}{$48 \mathrm{~mL}(p<0.0001)$} \\
\hline & \multirow{2}{*}{\multicolumn{2}{|c|}{ Rate of exacerbations** (/patient/year) }} & $\begin{array}{l}1.08 \text { (active); } \\
1.27 \text { (placebo) }\end{array}$ & $\begin{array}{l}1.21 \text { (active); } \\
1.49 \text { (placebo) }\end{array}$ \\
\hline & & & \multicolumn{2}{|c|}{ Rate ratio: $0.83(p<0.0003)$} \\
\hline
\end{tabular}

*based on GOLD criteria; **where a "moderate exacerbation" is one managed by initiating an oral or parenteral glucocorticosteroid; a "severe exacerbation"

requires hospitalisation and / or results in death 
of diarrhoea, weight loss, nausea, decreased appetite and headache were higher on average with roflumilast compared with placebo across the 52 weeks of the study, overall they were low ( $<10 \%$ of patients) for both treatment arms and there was no significant difference in cases of vomiting between roflumilast- and placebo-treated patients (unlike earlier PDE4inhibitors such as rolipram, which caused emesis).

Of the treatment-related adverse events noted, weight loss is causing the greatest concern. In the pooled analysis, the difference in weight change during the study between the roflumilast and placebo groups was $-2.17 \mathrm{~kg}$. The largest absolute weight decrease in patients treated with roflumilast was seen in obese patients, but significant weight loss was also reported among underweight patients. Further investigations are required to understand the mechanism of action.

\section{EOS and HELIOS}

\section{Study design}

These 24-week studies were designed to evaluate the efficacy of once-daily roflumilast in moderate to severe COPD patients concomitantly treated with a bronchodilator, either salmeterol (EOS) or tiotropium (HELIOS) compared with placebo. ${ }^{15}$ In contrast to the other trials, which required patients to have chronic cough and sputum production, patients recruited to EOS had stable disease. Analysis was carried out as intention to treat (ITT) with the primary endpoint being change in prebronchodilator $\mathrm{FEV}_{1}$.

\section{Baseline}

Aside from patients in the HELIOS study being more symptomatic due to their required presence of chronic bronchitis symptoms - cough and sputum production - and using at least 28 puffs per week of reliever medication the week before randomisation, the patient populations were broadly similar across both studies (see Table 2b).

\section{Efficacy outcomes}

Compared with placebo, roflumilast consistently improved mean pre-bronchodilator $\mathrm{FEV}_{1}$ in patients treated concomitantly with salmeterol or tiotropium compared with those on longacting bronchodilators plus placebo (see Table 2b). The improvement in lung function relative to placebo was sustained throughout the 6-month outcome period in both studies, irrespective of phenotypic characterisation of the trial populations (see Table 2b). Neither study was powered to show for exacerbations.

Furthermore, roflumilast had beneficial effects on other lung

Table 2b. Summary of roflumilast Phase II and III clinical trials, EOS and HELIOS. ${ }^{16}$

\begin{tabular}{|c|c|c|c|c|}
\hline & & & EOS & HELIOS \\
\hline \multirow[b]{5}{*}{ Study Design } & \multicolumn{2}{|c|}{ Treatment } & $\begin{array}{l}\text { salmeterol + roflumilast }(n=466) \\
\text { versus } \\
\text { salmeterol + placebo }(n=467)\end{array}$ & $\begin{array}{l}\text { tiotropium + roflumilast }(n=371) \\
\text { versus } \\
\text { tiotropium + placebo }(n=372)\end{array}$ \\
\hline & \multicolumn{2}{|c|}{ Roflumilast dose } & \multicolumn{2}{|l|}{$500 \mathrm{mcg}$} \\
\hline & \multicolumn{2}{|c|}{ Study duration } & \multicolumn{2}{|l|}{24 weeks } \\
\hline & \multirow{2}{*}{\multicolumn{2}{|c|}{ Population }} & Stable disease & $\begin{array}{l}\text { symptomatic of chronic bronchitis } \\
\text { (chronic cough, sputum production, } \\
\geq 28 \text { puffs of SABA weekly) }\end{array}$ \\
\hline & & & $\begin{array}{l}\text { - }>40 \text { years } \\
\text { - current or former smokers }(\geq 10 \\
\text { - } \mathrm{FEV}_{1} 40-70 \% \text { predicted } \\
\text { - } \mathrm{FEV}_{1} / \mathrm{FVC} \leq 0.70 \\
\text { - partial reversibility (to albuterol } 4 \\
\text { or } 200 \mathrm{~mL} \text { ) }\end{array}$ & years history) \\
\hline \multirow{6}{*}{ Baseline } & \multicolumn{2}{|c|}{ Prebronchodilator FEV $1 \%$ pred) } & $52 \%$ & $53 \%$ \\
\hline & \multicolumn{2}{|c|}{ Postbronchodilator $\mathrm{FEV}_{1}(\%$ pred) } & $50 \%$ & $56 \%$ \\
\hline & \multirow{3}{*}{$\begin{array}{l}\text { COPD } \\
\text { severity } \\
\text { by } \mathrm{FEV}_{1} \text { * }\end{array}$} & Moderate & $67 \%$ & $64 \%$ \\
\hline & & Severe & $33 \%$ & $33 \%$ \\
\hline & & Very severe & - & - \\
\hline & \multicolumn{2}{|c|}{ Gender (male) } & $66 \%$ & $80 \%$ \\
\hline \multirow{3}{*}{ Outcomes } & \multicolumn{2}{|c|}{$\begin{array}{l}\text { Mean change in pre-bronchodilator } \mathrm{FEV}_{1} \\
\text { relative to placebo arm }\end{array}$} & $\begin{array}{l}49 \mathrm{~mL} \\
(p<0.0001)\end{array}$ & $\begin{array}{l}80 \mathrm{~mL} \\
(p<0.0001)\end{array}$ \\
\hline & \multirow{2}{*}{\multicolumn{2}{|c|}{ Rate of exacerbations $s^{* *} \ddagger$ (/patient/year) }} & $\begin{array}{l}1.90 \text { (active); } \\
2.40 \text { (placebo) }\end{array}$ & $\begin{array}{l}1.80 \text { (active); } \\
2.20 \text { (placebo) }\end{array}$ \\
\hline & & & Rate ratio: $0.79(p=0.1408)$ & Rate ratio: $0.84(p=0.3573)$ \\
\hline
\end{tabular}

*based on GOLD criteria; **where a "moderate exacerbation" is one managed by initiating an oral or parenteral glucocorticosteroid; a "severe exacerbation" requires hospitalisation and / or results in death; $\neq$ underpowered 
function measurements and on selected patient-reported outcomes in both groups, including use of rescue medication and dyspnoea (shortness of breath questionnaire [SOBQ]) scores.

\section{Adverse events}

Overall, treatment-related adverse events were higher in the roflumilast than placebo arms in both studies (EOS: $18 \%$ vs 3\%; HELIOS: $14 \%$ vs $2 \%$, respectively). In descending order, the most frequently reported adverse events were: weight loss (EOS: $9 \%$ roflumilast vs $1 \%$ placebo; HELIOS: $6 \%$ roflumilast vs $1 \%$ placebo); diarrhoea (EOS: $8 \%$ roflumilast vs 3\% placebo; HELIOS: $9 \%$ roflumilast vs $1 \%$ placebo); nasopharyngitis (EOS: $7 \%$ roflumilast vs $7 \%$ placebo; HELIOS: $6 \%$ roflumilast vs $5 \%$ placebo); nausea (EOS: $5 \%$ roflumilast vs $<1 \%$ placebo; HELIOS: $3 \%$ roflumilast vs $1 \%$ placebo), and headache (EOS: $3 \%$ roflumilast vs $1 \%$ placebo; HELIOS: $2 \%$ roflumilast vs $0 \%$ placebo). No major differences in these adverse events was observed between the two studies. However, while there was no significant difference in patient withdrawal rates between the roflumilast and placebo arms in the HELIOS study $(p=0.0864)$, the difference was statistically significant in the EOS Study $(p=0.0019)$.

Incidence of vomiting was low across both studies and there was no significant difference in death, cardiovascular events or pneumonia in patients receiving roflumilast compared with the placebo groups. As in the one-year studies, weight loss was noted across all obesity categories for both groups. The average weight loss across the two trials was similar (mean loss of $2.1 \mathrm{~kg}$ ) with the main change more pronounced at six months of roflumilast treatment compared with placebo. The weight decrease at the 6month outcome period is at the same level seen after 12 months in the AURA and HERMES studies, which may suggest that it is an acute phenomenon that stabilises over time.

Overall the roflumilast adverse events profile was similar to that seen in the one-year AURA and HERMES studies with the majority of adverse events occurring at the beginning of treatment, being transient and not leading to sequelae.

\section{Licensed indication}

Roflumilast has been approved by the European Medicines Agency (EMEA) Committee for Medicinal Products for Human USE (CHMP) as a once-daily oral tablet (to be marketed as Daxas $\left.{ }^{\circledast}\right)$. It is indicated as maintenance treatment in severe COPD (i.e. in patients with post bronchodilator $\mathrm{FEV}_{1}<50 \%$ predicted) associated with chronic bronchitis in adult patients with a history of frequent exacerbations as an add-on to bronchodilator treatment. ${ }^{15}$ Marketing approval has not yet been received by the Food and Drug Administration in the United States.

\section{Identifying suitable patients in primary care}

The place of roflumilast is dictated by its current licence, but it remains to be established who should be offered this treatment in practice and also what advantages it offers over existing therapies.

There has been no direct comparison with theophylline or ICS. Roflumilast has an anti-inflammatory mode of action whereas any anti-inflammatory effects of theophylline are poorly quantified. Theophylline offers bronchodilation (at low cost) for patients with severe disease. It is recommended by GOLD, although its evidence base in COPD is limited..$^{5}$ While theophylline has potential benefits, the side effects (such as vomiting, drug interactions and cardiac arrhythmias) limit its use as does the need for blood level monitoring and its concomitant treatment with roflumilast is not recommended. There are limited data available at this time to guide clinicians as to the optimum use of add-on therapy in patients on maintenance bronchodilator therapy.

Among the true COPD patient population, phenotyping can help to identify those patients who might benefit from specific management interventions where the licence indication is narrow, as is the case for roflumilast. The legacy studies (OPUS and RATIO) that were used to inform the pre-licence trial programme for roflumilast suggest that PDE4 inhibitors are most likely to have a marked effect in patients with the chronic bronchitis COPD phenotype.

A study by Marsh et al. illustrates the complexity of identifying narrowly defined patient populations. ${ }^{26}$ The group aimed to determine the proportion of adult patients (aged $>50$ years) within each phenotypic subgroup of COPD (i.e. those with the chronic bronchitis, emphysema and/or asthma phenotype). Patients were selected from a random population-based survey and were given detailed questionnaires to complete, pulmonary function testing, and chest computed tomography (CT) scans. Of the 96 patients with COPD who completed the study, 19\% had the classical phenotypes of chronic bronchitis and/or emphysema but no asthma and 55\% had the asthma phenotype (see Figure 2). The study highlights the need for specificity when applying narrow licence indications in clinical practice. ${ }^{26}$

While integrating roflumilast into everyday COPD clinical practice, physicians must carefully identify appropriate patients i.e. those who have regular exacerbations, particularly if accompanied by cough and sputum production, and who remain symptomatic despite use of appropriate therapy for their COPD severity (i.e. combined short- and long-acting bronchodilators with or without ICS therapy in those with FEV 1 $<50 \%$ predicted) (see GOLD II and III steps in Figure 3).

COPD service reviews can now be used to identify patients suitable for roflumilast treatment by analysing routinely collected data from primary care care records supplemented by data obtained from patients. For example, in the UK, the Leicester County and Rutland Primary Care Trust review extends beyond normal practice audits by carrying out questionnaire-based 
Figure 2. Diagram incorporating axis-aligned proportional rectangles for each of the different phenotypes within the Wellington Respiratory Survey study population. The large black rectangle represents the full study group. The smaller black rectangle represents those with COPD (post-bronchodilator FEV $1 / F V C<0.7$ ). The white areas represent those who did not fulfil the criteria for chronic bronchitis, asthma or emphysema. ${ }^{26}$

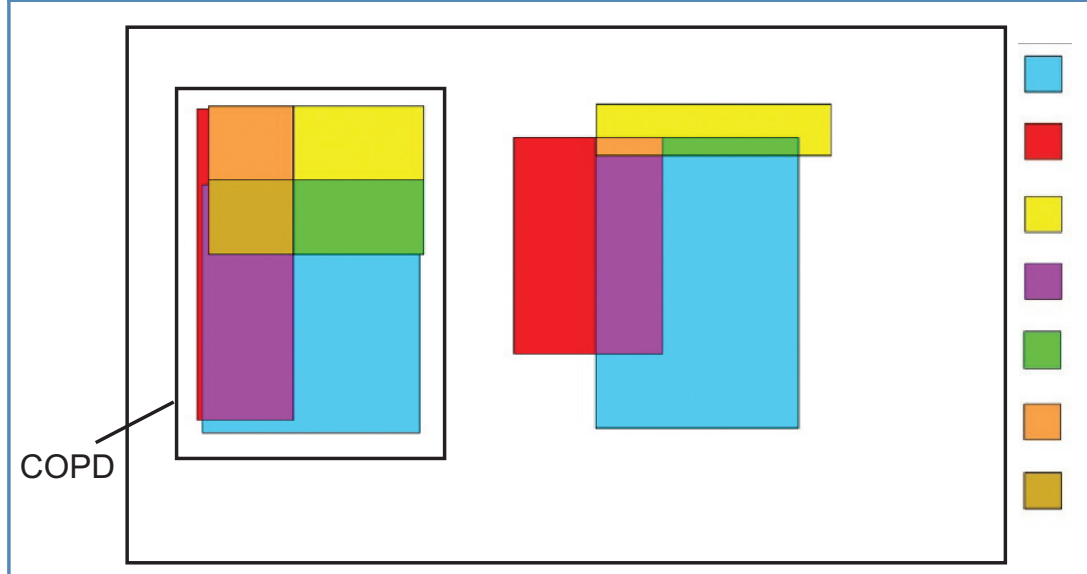

Asthma

Chronic bronchitis

\section{Emphysema}

Asthma and chronic bronchitis

Asthma and emphysema

Chronic bronchitis and emphysema

Asthma, chronic bronchitis and emphysema

Reprinted from Thorax, volume 63, Marsh SE, Travers J, Weatherall M, et al. Proportional classifications of COPD phenotypes, pages 761-7, Copyright (2008), with permission from BMJ Publishing Group Ltd

Figure 3. COPD treatment pathway indicating suggested role of PDE4-inhibitors (adapted by the authors from the Global Strategy for the Diagnosis, Management and Prevention of COPD (updated 2009), the Global Initiative for Chronic Obstructive Lung Disease (GOLD), www.goldcopd.org). ${ }^{5}$

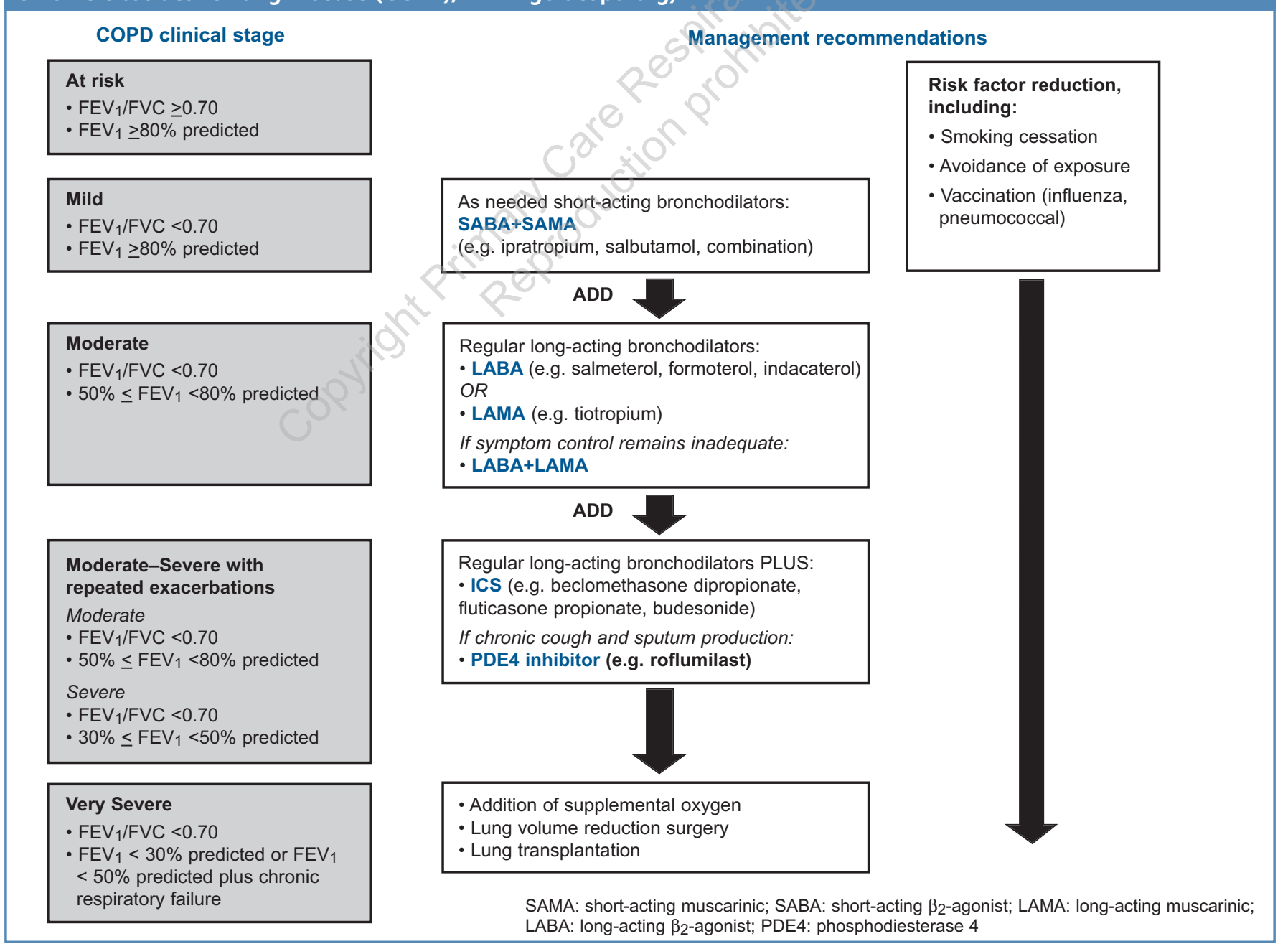


assessments of each COPD patient so as to identify and characterise those who are optimally managed (i.e. with symptoms minimised) and those who may require additional intervention according to local or national guidance. ${ }^{27}$ Electronic reports are sent to a lead GP at each participating practice and the audit information can be downloaded to the practice system and used to guide reviews of patients who may benefit from a change in their management approach. Thus, sub-optimally controlled patients who may benefit from additional therapy can be identified and characterised and their eligibility for add-on therapies (e.g. roflumilast) can be assessed.

\section{The role of roflumilast: research needs}

As discussed above, clear identification of patients eligible for roflumilast will require improved characterisation and phenotyping of patients in primary care. Thorough patient assessment should include lung function measurements, accurate health status classification and recording of chronic cough and regular sputum production to identify COPD patients with the chronic bronchitis phenotype accurately., 6.28 (see Table 3).

Furthermore, the degree of overlap between the mode of action of roflumilast and xanthines (e.g. theophylline) remains unclear at this time. It is thought that roflumilast works more intensively through just one of the numerous pathways used by

\begin{tabular}{|c|c|}
\hline \multicolumn{2}{|c|}{ Data to be recorded } \\
\hline $\begin{array}{l}\text { Additional } \\
\text { patient } \\
\text { characteristics }\end{array}$ & $\begin{array}{l}\text { - } \text { age } \\
\text { - sex } \\
\text { - } \text { weight } \\
\text { - height } \\
\text { - body mass index (BMI) } \\
\text { - } \text { comorbid disease }\end{array}$ \\
\hline $\begin{array}{l}\text { Lung function } \\
\text { measurements }\end{array}$ & $\begin{array}{l}\text { - } \mathrm{FEV}_{1} \\
\text { - Post bronchodilator FEV } 1 \\
\text { - } \mathrm{FEV}_{1} / \mathrm{FVC}\end{array}$ \\
\hline Health status & $\begin{array}{l}\text { - CAT: COPD Assessment Tool } \\
\text { - CCQ: Clinical COPD Questionnaire }\end{array}$ \\
\hline $\operatorname{DOSE}^{28}$ & $\begin{array}{l}\text { - D: dyspnea (MRC dyspnea score) } \\
\text { - O: airflow Obstruction - } \mathrm{FEV}_{1} \text { (as above) } \\
\text { - S: smoking status } \\
\text { - E: exacerbation frequency (annual rate) }\end{array}$ \\
\hline $\begin{array}{l}\text { Evidence of } \\
\text { phenotype }\end{array}$ & $\begin{array}{l}\text { - Chronic bronchitis (chronic cough with } \\
\text { regular productive cough), and/or } \\
\text { - Emphysema, and/or } \\
\text { - Asthma }\end{array}$ \\
\hline \multicolumn{2}{|c|}{$\begin{array}{l}\text { Reference 28: Jones RC, Donaldson GC, Chavannes NH, Kida K, } \\
\text { Dickson-Spillmann M, Harding S, Wedzicha JA, Price D, Hyland ME. } \\
\text { Derivation and validation of a composite index of severity in chronic } \\
\text { obstructive pulmonary disease: the DOSE Index. Am J Respir Crit Care Med } \\
\text { 2009;180:1189-95 }\end{array}$} \\
\hline
\end{tabular}

xanthines - theophylline is thought to be a weak and nonselective inhibitor of PDEs with less than $10 \%$ inhibition of PDE4, ${ }^{29}$ in comparison to roflumilast which achieves 30-60\% inhibition of PDE4 subtypes. ${ }^{30}$ However, further evaluation of the safety of PDE4-inhibitors (which appear to have a positive safety profile in comparison with xanthines) is required, as is greater understanding of the inflammatory pathways at work in COPD and how roflumilast (and existing therapies) inhibit the underlying disease processes.

Other important areas for further research, which will play an important role in establishing roflumilast's future role in COPD treatment, include thorough evaluations of the potential overlap, synergies and/or additive effects of:

- roflumilast and ICS therapy

- and roflumilast as add-on therapy to long-acting anticholinergics and combination therapy.

Cost-effectiveness evaluations are also required, as is determination of the mechanism underlying the weight loss seen in the Phase III studies.

The clinical trials carried out to date have focussed largely on evaluation of the efficacy of roflumilast in patients with the chronic bronchitis COPD phenotype (i.e. sputum producers). However, a phenotypic interpretation of the role of roflumilast may be superficial. An improvement in $\mathrm{FEV}_{1}$ was recorded regardless of the COPD phenotype, i.e. among sputum producers - as in AURA, HERMES and HELIOS - and also among nonsputum producers, as in EOS. Further work is required to establish whether the potential benefits of roflumilast are restricted to the chronic bronchitis phenotypic sub-group of COPD patients who are sputum producers at high risk of exacerbations, or whether the response could be achieved in all exacerbators regardless of severity based on lung function.

\section{Conclusions}

COPD exacerbations are associated with increased upper and lower airway inflammation. They lead to increased sputum production, worsening airflow limitation, development of dynamic hyperinflation and a poorer COPD prognosis. Systemic inflammation also increases around episodes of exacerbations and is thought to be the result of a "spill-over" of inflammatory markers from the lungs. ${ }^{6}$

The PDE4-inhibitor roflumilast represents a new class of antiinflammatory drug in COPD. The clinical trial data show that roflumilast improves lung function and reduces exacerbation rates in COPD compared with placebo, independent of smoking status and concomitant therapy with LABA. A significant and sustained improvement in lung function has also been recorded with roflumilast compared with placebo when used as an addon treatment to concomitant bronchodilator (LABA or LAMA) therapy. ${ }^{14,15}$

As a result of informative early study work, the pre-licence 
trials focused on those patients considered most likely to respond to roflumilast - patients with severe COPD associated with chronic bronchitis with a history of exacerbations, as reflected in the licence indication. ${ }^{16}$ Key to realising the anticipated clinical benefits will be clear phenotyping of patients in clinical practice to guide appropriate prescribing.

\section{Acknowledgements}

The writing of this manuscript was supported by an unrestricted educational grant from Nycomed UK Ltd.

\section{Conflict of interest declarations}

David Price has consultant arrangements with Boehringer Ingelheim (BI), GlaxoSmithKline (GSK), Merck, Novartis and Teva. He or his research team have received grants and support for research in respiratory disease from the following organisations in the last 5 years: UK National Health Service, Aerocrine, AstraZeneca (AZ), BI, GSK, Merck, Novartis, Nycomed, Pfizer and Teva. He has spoken for: Boehringer Ingelheim, Chiesi, GlaxoSmithKline, Merck, Pfizer and Teva. He has shares in AKL Ltd which produces phytopharmaceuticals. He is the sole owner of Research in Real Life Ltd.

Alison Chisholm has no conflict of interest to declare.

Dermot Ryan has lectured on behalf of, received sponsorship from or provided consulatnacy services to: AZ, GSK, MSD, Schering Plough, Uriach Pharma, Chiesi, Nycomed, BI, Pfizer and Novartis Pharma.

Alan Crockett has no conflict of interest to declare.

Rupert Jones has been paid to take part in advisory boards related to COPD for BI, GSK, Novartis, Nutricia, Pfizer, TEVA and in the last 3 years. RJ has spoken at scientific / educational meetings financed by Altana, AZ, BI, GSK, MSD, Pfizer, Tejin and Trinity Chiesi in the last 3 years. He is a consultant on the global emPOWER educational programme supported by Pfizer and Boehringer Ingelheim.

\section{References}

1. World Health Organization. World Health Statistics 2008. Available online at http://www.who.int/whosis/whostat/2008/en/index.html [Last accessed: 6/11/09].

2. Healthcare Commission. Clearing the air: A national study of chronic obstructive pulmonary disease. Healthcare Commission, 2006

3. Tinkelman DG, Price DB, Nordyke RJ, Halbert RJ. Misdiagnosis of COPD and Asthma in Primary Care Patients 40 Years of Age and Over. I Asthma 2006;43(1):75-80. http://dx.doi.org/10.1080/02770900500448738

4. Price D, Freeman D, Cleland J, Kaplan A, Cerasoli F. Earlier diagnosis of COPD in primary care and earlier treatment. Prim Care Resp J 2010. http://dx.doi.org/10.4104/pcri.2010.00060

5. Global Initiative for Chronic Obstructive Lung Disease. Global strategy for the diagnosis, management, and prevention of chronic obstructive pulmonary disease. 2009 update. www.goldcopd.com. Last accessed 1-12-2009

6. National Institute for Clinical Excellence. Chronic obstructive pulmonary disease: management of chronic obstructive pulmonary disease in adults in primary and secondary care. Clinical guideline 12. Thorax 2004;59(Suppl I):i1-i232.

7. Levy ML, Fletcher M, Price DB, Hausen T, Halbert RJ, Yawn BP. International Primary Care Respiratory Group (IPCRG) Guidelines: diagnosis of respiratory diseases in primary care. Prim Care Resp J 2006;15:20-34. http://dx.doi.org/ 10.1016/j.pcrj.2005.10.004

8. O'Donnell DE, Aaron S, Bourbeau J, et al. Canadian Thoracic Society recommendations for management of chronic obstructive pulmonary disease 2007 update. Can Respir J 2007;14 Suppl B:5B-32B.

9. Celli BR, MacNee $W$, and committee members. Standards for the diagnosis and treatment of patients with COPD: a summary of the ATS/ERS position paper. Eur Respir J 2004;23:932-46. http://dx.doi.org/10.1183/09031936.04.00014304

10. Tashkin D, Rennard S, Taylor Hays J, et al. Efficacy and safety of varenicline for smoking cessation in patients with mild to moderate COPD. Chest Meeting
Abstracts. 2009;136:151S-b-152S-b.

11. Poole PJ, Black PN. Mucolytic agents for chronic bronchitis and chronic obstructive pulmonary disease. Cochrane Database Syst Rev 2006;3:CD001287.

12. Fletcher $C M$, Elmes $P C$, Fairbairn $M B$, et al. The significance of respiratory symptoms and the diagnosis of chronic bronchitis in a working population. BMJ 1959:2:257-66.

13. Singh D, Brooks J, Hagan G, et al. Superiority of "triple" therapy with salmeterol/fluticasone propionate and tiotropium bromide versus individual components in moderate to severe COPD. Thorax 2008;63(7):592-8. http://dx.doi.org/10.1136/thx.2007.087213

14. Calverley PM, Rabe KF, Goehring UM, et al. Roflumilast in symptomatic chronic obstructive pulmonary disease: two randomised clinical trials. Lancet 2009;374(4691):685-94. http://dx.doi.org/10.1016/50140-6736(09)61255-1

15. Fabbri LM, Calverley PM, Izquierdo-Alonso JL, et al. Roflumilast in moderate-tosevere chronic obstructive pulmonary disease treated with long-acting bronchodilators: two randomised clinical trials. Lancet 2009; 374(4691):695-703. http://dx.doi.org/10.1016/S0140-6736(09)61252-6

16. European Medicines Agency Science Medicines Health. Summary of opinion (initial authorisation) Daxas: roflumilast. 22 April 2010. Available online at: http://www.ema.europa.eu/pdfs/human/opinion/Daxas_15986110en.pdf

17. Maclntyre NR. Chronic obstructive pulmonary disease: emerging medical therapies. Respir Care 2004;49(1):6-9.

18. Pettersen CA, Adler KB. Airways Inflammation and COPD. Chest 2002;121(5 Suppl):142S-150S. http://dx.doi.org/10.1378/chest.121.5_suppl.142S

19. Molet $S$, Belleguic $C$, Lena $H$, et al. Increase in macrophage elastase (MMP-12) in lungs from patients with chronic obstructive pulmonary disease. Inflammation Res. 2005;54(1):31-6. http://dx.doi.org/10.1007/500011-004-1319-4

20. Barnes PJ. Mechanisms in COPD: Differences from asthma. Chest 2000;117(2 Suppl):10S-14S. http://dx.doi.org/10.1378/chest.117.2_suppl.10S

21. Barnes PJ. COPD: is there light at the end of the tunnel? Curr Opin Pharmacol 2004;4(3):263-72. http://dx.doi.org/10.1016/j.coph.2004.03.001

22. Barnes PJ, Hansel TT. Prospects for new drugs for chronic obstructive pulmonary disease. Lancet 2004;364(9438):985-96. http://dx.doi.org/10.1016/S01406736(04)17025-6

23. Dastidar SG, Ray A, Shirumalla R, et al. Pharmacology of a novel, orally active PDE4 inhibitor. Pharmacology 2009;83(5):275-86. http://dx.doi.org/10.1159/000209608

24. Martinez FJ, Calverley PMA, Goehring UM, et al. Defining patient populations in COPD: Experience with roflumilast. COPD7 2010; Abstract 12. Available at: http://www.copdconferences.org

25. Humbert M, Beasley R, Ayres J, et al. Benefits of omalizumab as add-on therapy in patients with severe persistent asthma who are inadequately controlled despite best available therapy (GINA 2002 step 4 treatment): INNOVATE. Allergy 2005;60(3):309-16. http://dx.doi.org/10.1111/j.1398-9995.2004.00772.x

26. Marsh SE, Travers J, Weatherall M, et al. Proportional classifications of COPD phenotypes. Thorax 2008;63(9):761-7. http://dx.doi.org/10.1136/ thx.2007.089193

27. Optimum Patient Care. Audit Review Services. May 2010. Available online at: http://www.optimumpatientcare.org/audit/audit.html

28. Jones RC, Donaldson GC, Chavannes NH, et al. Derivation and validation of a composite index of severity in chronic obstructive pulmonary disease: the DOSE Index. Am J Respir Crit Care Med 2009;180:1189-95. http://dx.doi.org/ 10.1164/rccm.200902-02710C

29. Poolson JB, Kazanowski JJ, Goldman AL, Szentivanyi A. Inhibition of human pulmonary phosphodiesterase activity by therapeutic levels of theophylline. Clin Exp Pharmacol Physiol 1978;5:535-39. http://dx.doi.org/10.1111/j.14401681.1978.tb00707.x

30. Lahu G, Huennemeyer A, von Richter O, et al. Effect of Single and Repeated Doses of Ketoconazole on the Pharmacokinetics of Roflumilast and Roflumilast N-Oxide. J Clin Pharmacol 2008;11:1339-49. http://dx.doi.org/10.1177/0091270008321941

Available online at http://www.thepcrj.org 